\title{
Palliative Effects of Daonil Supplemented with Tryptophan on Alloxan Induced Diabetic Rats
}

\author{
Emili Augustina Mmaduaburochukwu ${ }^{1}$, Osadolor H.B ${ }^{2}$, Omorodion Nosa Terry ${ }^{1 *}$, Ibeh N.I ${ }^{1}$ \\ ${ }^{I}$ Department of Medical Laboratory Science, School of Basic Medical Sciences, University of Benin, Nigeria \\ ${ }^{2}$ Health Services Department, University of Benin, Nigeria
}

"Corresponding Author: Nosa Terry Omorodion, Department of Medical Laboratory Science, School of Basic Medical Sciences, University of Benin, Benin City, Nigeria, E-mail: terry.omorodion@ uniben.edu

\begin{abstract}
Diabetes mellitus is a metabolic disorder characterized by high glucose levels in the blood. It constitutes a major health concern today because the prevalence has continuously increased worldwide over the past few decades affecting about $2.8 \%$ of the world population. This study examine the palliative effect of daonil supplemented with tryptophan on alloxan induced diabetic rats and the possible benefit of the treatment. Since carbohydrate metabolism is modified in diabetic animals, it's of interest to determine the effect of tryptophan on alloxan induced diabetic rat. To identify possible relationships between tryptophan with diabetes. The purpose of this study was to ascertain if tryptophan administration has positive effect on the glucose level. Twenty five healthy female rats out of 30 were made diabetic by dissolving 150mg alloxan monohydrate per $\mathrm{kg}$ weight in $0.9 \mathrm{ml}$ of normal saline which was injected into the rats intraperitoneally. After the establishment of diabetes the animals were subdivided into three groups of 4 each. Daonil and tryptophan only were administered orally to group 1 daily for 7 days, Tryptophan only for group 2 and daonil only for group 3 while the group 4 of five served as controls. Tryptophan was administered at $400 \mathrm{mg} / \mathrm{kg}$ and $0.5 \mathrm{ml}$ of daonil. The weight of the animals were recorded, and the glucose levels was determined using the glucometer on the the 3rd and 7th day. Histomorphological studies were conducted on the kidney, liver and pancreas tissues using light microscope method. Daonil and tryptophan treated rats (groupl) and Tryptophan only treated rats (group 2), showed no significant decrease $(P<0.318)$ in glucose level. Treatment with daonil showed a significant decrease $(P>0.01)$ in weight and glucose concentration. The histomicrograph for the three treatments showed that the kidney renal corpuscles appeared as atrophied dense rounded structures bounded by inflammatory infiltrates. Liver show thickened distorted portal vein with clear visible fatty hydropic changes and congested with some visible inflammatory cells. Pancreas pyknotic nuclei of some acinar cells appeared normal with some islet-cells showing congested pyknotic nuclei with lymphocytic infiltrates. The findings in this study indicate that diabetes had deleterious effect on the kidney, liver and pancreas due to drug administration and also tryptophan supplement was not a good alternative for diabetes management.
\end{abstract}

Keywords: Diabetes, Daonil, Tryptophan

\section{INTRODUCTION}

Diabetes is a condition that arises when the pancreas do not produce enough insulin, or when the body cannot effectively use the insulin produced. Diabetes Mellitus is a group of metabolic diseases characterized by high glucose levels in the blood over a prolonged period [1]. It is due to several pathogenic processes ranging from infection, and uncommon forms of immune-mediated diabetes, autoimmune destruction of the $\beta$-cells of the Islet of Langerhans of the pancreas with resultant insulin deficiency to abnormalities that result in resistance to insulin action [1]. Defects in insulin secretion and action usually co-exist in the same patient. These conditions leads to abnormalities in carbohydrate, fat and protein metabolism. There are three main types of diabetes mellitus: type 1 diabetes, type 2 diabetes, and gestational diabetes. Other causes of diabetes are genetic defects in insulin action, diseases of the exocrinepancreas, gene $11 \mathrm{C}$ defects of the $\beta$-cell, endocrinopathies, drug or chemical induce diabetes, infections, uncommon forms of immune-mediated diabetes and genetic syndromes due to chromosomal abnormalities. Skin rashes can occur in diabetes and it is known as diabetic dermatomes. Type 1 diabetes was formally referred to as insulin- dependent 
diabetes mellitus (IDDM) or juvenile diabetes. It accounts for only $5-10 \%$ and is due to cellular T3 cells mediated autoimmune destruction of the $\beta$ diabetic-cell of the pancreas by some makers like islet cell auto-antibodies, autoantibodies to insulin, auto-antibodies to glutamic acid decarboxylase (GAD65) and autoantibodies to the tyrosine phosphatises 1A-2 and $1 \mathrm{~A}-2 \beta$. These auto antibodies are detected in about $85-90 \%$ of individuals with this disease. Type $1 \mathrm{DM}$ constitutes < $3 \%$ of diabetic patients in Nigeria [2].Type $2 \mathrm{DM}$ also referred to as non-insulin dependent diabetes or adult onset diabetes is caused primarily by family history, excessive body weight and lack of enough exercise which results in the body tissues responding defectively to insulin secretion [3]. This form of diabetes accounts for approximately $90-95 \%$. The risk of developing type 2 diabetes increase with age, obesity, lack of physical activity and diet. It constitutes about $96 \%$ of Nigerians living with diabetes while about $50 \%$ of patients with type 2 diabetes are asymptomatic, and it remains undiagnosed for many years. Genetic mutations (autosomal or mitochondrial) can lead to defects in beta cell function. Abnormal insulin action may also have been genetically determined in some cases. Any disease that causes extensive damage to the pancreas may lead to diabetes (for example, chronic pancreatitis and cystic fibrosis). Diseases associated with excessive secretion of insulin-antagonistic hormones can cause diabetes (which is typically resolved once the hormone excess is removed). Many drugs impair insulin secretion and some toxins damage pancreatic beta cells. Other forms of diabetes mellitus include congenital diabetes, which is due to genetic defects of insulin secretion, cystic fibrosis-related diabetes, steroid diabetes induced by high doses of glucocorticoids, and several forms of monogenic diabetes [4]."Type 3 diabetes" has been suggested as a term for Alzheimer's disease as the underlying processes may involve insulin resistance by the brain [5] . Gestational diabetes mellitus (GDM) is defined as any degree of glucose intolerance first observed during pregnancy. It resembles type $2 \mathrm{DM}$ because it involves the combination of relatively inadequate insulin secretion and responsiveness. It occurs in about $2-10 \%$ of all pregnancies and may persist or disappear after delivery [6]. There is growing prevalence of people living with diabetes in the world varying from country to country, race and ethnic group. In 2014, about 422 million adults (or $8.5 \%$ ) of the population had diabetes compared with 108 millions $(4.7 \%)$ in 1980 [2]. The number of people suffering from diabetes in Africa remain uncertain, however International Diabetes Foundation (IDF) estimate in 2000 put the figure at 7.5million diabetics adults between ages 2079year which figure is going to be much larger in future years because WHO and IDF estimate that the number will double over the next 25 years in Africa. Diabetes is becoming a pressing health problem for Sub Saharan Africa because diabetic treatment imposes great cost on families and also hinders their capacity to pay through the loss of income of the diabetic member. Sub Saharan Africa like the rest of the world is experiencing an increasing prevalence of diabetes along other communicable disease. In 2010, 12.1 million people were estimated to be living with diabetes in Africa and this is projected to increase to 23.9 million by the year 2030. Nigeria with over 250 ethnic groups, with different culture and food values have no current uniform record on the prevalence of diabetes although there have been steady increase over the past 30years according to the data recorded by [7] at Ibadan $(0.4 \%), 1986(1.6 \%)$ at Lagos for undiscovered diabetes by Ohwovoriole et al FMOH (2.2\%) National, highest in Lagos Island (7\%), lowest in Mangu in Plateaus state, in 1994 Puepet had undiscovered diabetes $(3.1 \%)$ in Jos metropolis and by 2004 it rose to $(10.3 \%)$. World health organisation (WHO), International federation of Diabetes (IFD), and Diabetes Association of Nigeria (DAN) said that the country with the highest number of people living with diabetes and also with the highest mortality rate from the disease in Africa is Nigeria. About 5million people are still living with diabetes, 40,815 adult died due to diabetes and more than 1.56million diabetic cases recorded in 2015 in Nigeria. Also in 2012, 1.5 million death was recorded. In most developed countries diabetes is the leading cause of death, each year about three million death that occurred are diabetes related according to IFD. Diabetes epidemic are having a major health and socio economic impact especially in developing countries. The progressive increase in this prevalence rates is attributed to factors that can easily be modified such as dietary and lifestyle changes, overweight and obesity, physical inactivity, cigarette smoking and alcohol consumption [8]. Diabetes is commonly regarded as incurable, and all effort is directed at controlling or managing it. Tryptophan is an essential, nonpolar, aromatic $\alpha$-amino acid used for synthesis 
of protein. It is a precursor for the neurotransmitters serotonin and melanin [9]. Serotonin (5-HT), is an important neuro transmitter with physiological activity [10]. Tryptophan has a role in physiological (nerve transmission, immune response) and pathological processes (depression, stress, sleep and appetite disorders) [11] and therefore its plasma levels are linked to changes in mood, behaviour, anxiety, sleep, fatigue and appetite suppression [12]. The vitamin niacin and a phytohormone auxin are also synthesized from tryptophan. As an essential amino acid, tryptophan is not synthesized from most basic substances in humans and other animals, we must ingest tryptophan or tryptophan-containing proteins. Tryptophan is a routine constituent of most protein-based foods or dietary proteins. It is particularly plentiful in chocolate, oats, dried dates, milk, yogurt, cottage cheese, red meat, eggs, fish, poultry, sesame, chickpeas, almonds, sunflower seeds, pumpkin seeds, spirulina, bananas, and peanuts. It has been demonstrated in both animal and human tests that ingestion of a meal rich in carbohydrates triggers release of insulin [13]. Insulin in turn stimulates the uptake of large neutral branched-chain amino acids (BCAA), but not tryptophan into muscle, increasing the ratio of tryptophan to BCAA in the blood stream. The resulting increased tryptophan ratio reduces competition at the large neutral amino acid transporter (which transports both BCAA and aromatic amino acids), resulting in more uptake of tryptophan across the blood-brain barrier into the cerebrospinal fluid (CSF) [14]. In human tryptophan degradation also yields precursors for glucose synthesis. It was observed that oral administration of $400 \mathrm{mg}$ of tryptophan resulted in marked increases in blood glucose in diabetic rats but had no marked effect in normal rats. Tryptophan appeared to be about one-fourth as active as glucose in elevating the blood glucose curves of diabetic rats. Data from previous work indicate that tryptophan does increase blood glucose in fasted diabetic rats, they do not necessarily mean that tryptophan was being converted to glucose [15]. It is possible that tryptophan promoted the formation of glucose in some indirect manner. The increase in blood glucose levels resulting from administration of tryptophan to diabetic rats suggests that these rats may convert tryptophan to glucose in an attempt to supply energy rather than converting it to niacin [16]. Alloxan (2,4,5,6tetraoxypyrimidine; 2,4,5,6-pyrimidinetetrone) is an oxygenated pyrimidine derivative which is present as alloxan hydrate in aqueous solution and it is also known as a drug used to induce diabetes. The drug has been noted to exert its diabetogenic action when administered parenterally, i.e., intravenously, intraperitoneally or subcutaneously. The dose of alloxan required for inducing diabetes depends on the animal species, nutritional status and route of administration [17]. Moreover, alloxan has non-toxic effect to the human beta-cells, even in very high doses, which is due to the differing glucose uptake mechanisms in humans and rodents [18]. Alloxan is one of the most commonly used chemical for induction of diabetes mellitus. It is a well- known diabetogenic agent widely used to induce Type 11 diabetes in animals [19]. Daonil an oral diabetic drug used to control blood sugar level in patient with mild to moderate type-2 diabetes mellitus who are unable to consistently achieve adequate normal blood sugar levels with diet and exercise alone. Daonil tablets $5 \mathrm{mg}$ contain glibenclamide, an oral anti hyperglycaemic drug which belongs to a group of medicine called sulphonylurease [20]. It lowers blood glucose primarily by acting directly on the insulin-producing beta cells of pancreatic islet tissue, to increase their sensitivity to glucose and to stimulate the cells to produce and release more insulin, it also acts on insulin-responsive cells in the muscle, fat and liver cells by increasing the number of receptors, because of the effectiveness of insulin in controlling glucose production by the liver and the uptake of insulin into peripheral tissues for energy and storage [21]. It can be used alone as monotherapy with diet and exercise, or in combination with other antihyperglycaemic drug like metformin, when a single drug does not provide desired glycaemic control. Maintaining adequate glucose level control with daonil tablets $5 \mathrm{mg}$ reduces the risk of developing vascular complications. Although some drugs interact with daonil by either causing hyperglycaemia by weakening the blood glucose control effect or lower blood glucose by increasing the lowering effect. There are transient and more serious side effect associated with daonil medication [22,23]. The aim of this study is to provide information on how tryptophan and daonil concentration can ameliorate hyperglycaemia using animal models. The objective of the study is to evaluate the effects of tryptophan and daonil on diabetes, can tryptophan level cause positive glucose reduction or increase already elevated glucose and also to see if daonil still have anti diabetic 
action on rats. Since carbohydrate metabolism is modified in diabetic animals, it's of interest to determine the effect of tryptophan on alloxan induce diabetic rat. To identify possible relationships between tryptophan with diabetes. The purpose is to ascertain if tryptophan administration have positive effect on the glucose level. Will tryptophan be used to treat diabetes, also if people living with diabetes be encouraged to consume food very rich in tryptophan.

\section{MATERIALS AND METHODS}

Healthy 30 adult female wistar rats weighing between $96 \mathrm{~g}-250 \mathrm{~g}$ were used for this study. The rats were brought from the animal house of the Department of Anatomy Faculty of Basic Medical Sciences, University of Benin. Animals were placed in 5 different well ventilated wire mesh cages with 6 rats in each. Rats were kept under controlled light (light 7am-7pm, dark 7pm-7am), temperature $\left(21 \pm 2^{\circ} \mathrm{C}\right)$ and humidity $(55 \pm 10 \%)$ conditions. They had free access to water and were fed ad libitum on a commercial diet (TOP FEED GROWER MASH) and renewed daily. The rats were acclimatised for two week. In the present study only female animals were used. It is not known whether sex would have influenced the findings. The alloxan used for the study was alloxan monohydrate (Sigma Aldrich, St. Louis, MO, USA; stored at $4^{\circ} \mathrm{C}$ ) was dissolved in normal saline at room temperature and was injected by intraperitoneal routes with varying concentration according to their various weight. The tryptophan is of analytical grade of $5 \mathrm{~g}$ produce by (JHD) Guangdang Guanghua Chemical Factory company limited Sharfau Guandang, China. $400 \mathrm{mg}$ was orally administered to the rats according to their weight. The $5 \mathrm{mg}$ tablet of daonil was purchased from Ziloy Pharmacy at Benin Office ugbowo and was given orally in $0.5 \mathrm{mg}$ dose daily for seven days.This experiment was carried out in three stages. Stage 1: After two weeks of acclimatization the rats were divided into five groups of six. The animals were allowed to fast for 18 hours then their body weight was taken and basal fasting blood glucose (FBG) determined. Twenty-five female wistar rats were made diabetic by injecting them intraperitoneally with single dose of $150 \mathrm{mg} / \mathrm{kg}$ alloxan monohydrate, diluted in $0.9 \%$ normal saline at room temperature [24].The control group of 5 were not induced. The rats were allowed to resume feeding and drinking of water
30 minutes after drug administration. The effect of alloxan to chemically establish the diabetic condition was assessed by using 15 scalpel blade to make an incision in any of the four veins in the tail of the rat and glucose concentration was analysed from the blood sample. Blood glucose level greater than $150 \mathrm{mg} / \mathrm{dl}$ in rats were considered diabetic [2]. But in this study the rats with a blood glucose level $>250 \mathrm{mg} / \mathrm{dl}$ were considered to have developed experimental diabetes and were therefore selected for treatment. The blood glucose level was determine on the $3 \mathrm{rd}$ and $7^{\text {th }}$ day using Accu-chek active glucometer and test strip. Although some of the rat died 48 hour after induction and more died on the $5^{\text {th }}$ and $6^{\text {th }}$ day. Unfortunately, an autopsy was not performed on these animals. Stage 2: In the second stage the diabetic rats were re-grouped into three (A, B and C). Each group was treated differently. Group A was daily administered with $400 \mathrm{mg} / \mathrm{kg}$ tryptophan and $0.5 \mathrm{ml}$ of daonil orally for 7 days. The weight and glucose level on the 3 th and $7^{\text {th }}$ day was determined respectively. Group B was treated only with $400 \mathrm{mg} / \mathrm{kg}$ tryptophan orally on a daily basis for 7 days. The blood glucose level and weight was determine on the $3 \mathrm{rd}$ and $7^{\text {th }}$ day. Group $\mathrm{C}$ was treated only with $0.5 \mathrm{ml}$ of $5 \mathrm{mg}$ daonil orally for 7days.The weight and blood glucose was determine on the 3 th and $7^{\text {th }}$ day. During this second stage no death was recorded. Stage 3: In this stage the animals were sacrificed and organs removed for histological analysis. Before the animals were sacrificed they were anaesthetized with chloroform in a plastic dome and sacrificed. The kidney, liver and the pancreas were harvested and immediately fixed in $10 \%$ neutral buffered formalin solution.Each animal was taken out from the cage and placed in another smaller cage for easy access to the tail which is swabbed with methylated spirit and a little pressure was applied to the tail for easy flow of blood then incision was made on the vein in the tail and the blood glucose concentration of each rat was determine using Roche Accu-chek active glucometer and test strips. The glucose meter is based on electrochemical technology, by using electrochemical test strips to perform the measurement. In each test strip, the enzyme glucose oxidase reacts with the glucose in the blood sample and forms gluconic acid. The gluconic acid then reacts, with another chemical ferricyanide. The combination of ferricyanide 
and the gluconic acid then forms ferrocyanide which causes the device to run an electronic current through the blood sample on the strip. This current then read the ferrocyanide which determine the amount of glucose in the blood sample it is digitally displayed on the screen of the glucose testing meter [25]. Although various factors like meter calibration, optimal temperature, size and quality of blood sample, dirt on meter, humidity, and aging of test strips can affect the accuracy of result, all these were put into consideration in the course of this study during the analysis. The test strips used in this study was coded hence the accuracy of the blood glucose meter is not compromised due to lack of calibration. The analysis was repeated for the days the glucose concentration was determined. After the tissue were harvested from the animals they were preserved using 10\% Neutral buffered formalin and placed in pre labelled universal containers. The tissues were taken to the histopathology laboratory at the University of Benin teaching hospital. Using all standard safety operating procedures tissues were dissected and placed in labelled tissue cassettes The thickness of tissues did not exceed $3-5 \mathrm{~mm}$. Tissues were then subjected to automatic tissue processing using the Leica TP2010 automatic tissue processor for 18hours passing them through the four stages of tissue processing namely : fixation (using 10\% neutral buffered formalin) dehydration (using ascending grades of isopropyl alcohol), clearing or dealcoholisation ( using xylene) and finally impregnation or infiltration using molten paraffin wax. The tissues were then embedded in paraffin wax using the Leica automatic tissue embedder and sectioned to get ultrathin sections at 5 microns; using the thermo scientific semi automatedrotary microtome. Tissues were floated out from the thermo scientific digital floating bath on frosted end pre labelled slides and dried on the thermo scientific digital slim line hot plate. Tissues were further dried in the hot air oven overnight and subjected to haematoxylin and eosin staining to demonstrate the general tissue structure. Stained slides were mounted in DPX and allowed to dry before viewing under the microscope using X100 and X400 magnification [26]. The data were carefully entered, checked and properly coded into Microsoft excel software package. Statistical analysis was carried out using the statistical package for Social Sciences (SPSS) version 20.0 (Chicago-IL, USA). Results were expressed as Mean + Standard Error of the Mean. One way Analysis of Variance (ANOVA) was used for comparing means to determine if there was significant difference between more than two groups. Pearson Correlation coefficient was used for determining relationship between measured parameters weight and concentration of glucose. These were also subjected to Duncan multiple range test (DMR).

\section{Results}

\subsection{Physical Examination of Animals}

The animals showed a little restlessness the moment they were induced and few minute later became stable and because they were deprived of food and water they appear a bit weak but the moment they resume feeding 30 minutes later they became active again. It was noted that some of the animals sleep more. It was also observed that during blood collection that the animals express pain and attempted to bit and to escape. It was observed that some of the animals died few hours after induction but no death was recorded during the daily administration of tryptophan and daonil in the different groups. The animals in the control group experience were totally different. After the animals were sacrificed, it was observed that the liver, kidney and pancreas in the three groups were enlarged, looked inflamed and the coloration of the organs were different from the ones in the control group. From Table 4.1 it was observed that there was a mean significant difference in weight and glucose level on the $3^{\text {rd }}$ and $7^{\text {th }}$ day after alloxan induction for weight $(\mathrm{p}<0.01)$ and glucose $(\mathrm{p}<0.001)$.

Table4.1. Comparison of Mean ( \pm ) SEM of Weight and Glucose Level for Groups 1-4.

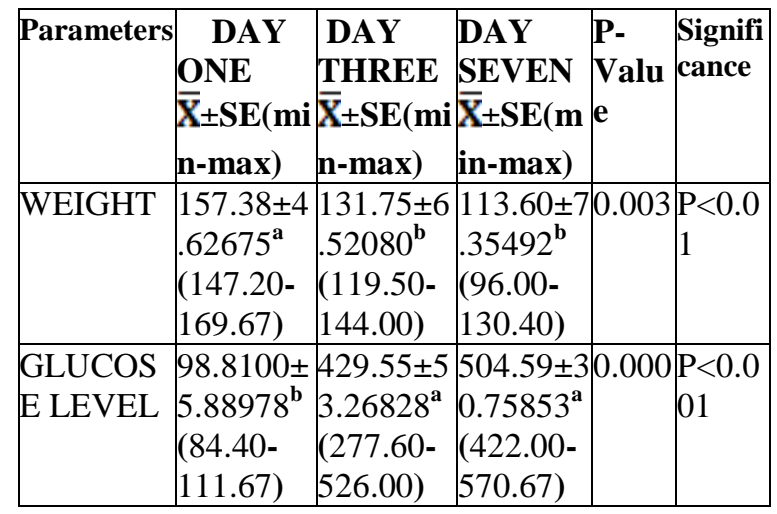

$* P<0.01=$ high significant difference, $P<0.001=$ very high significant difference, Similar letters indicate means that are not significantly different $(P>0.05)$. 


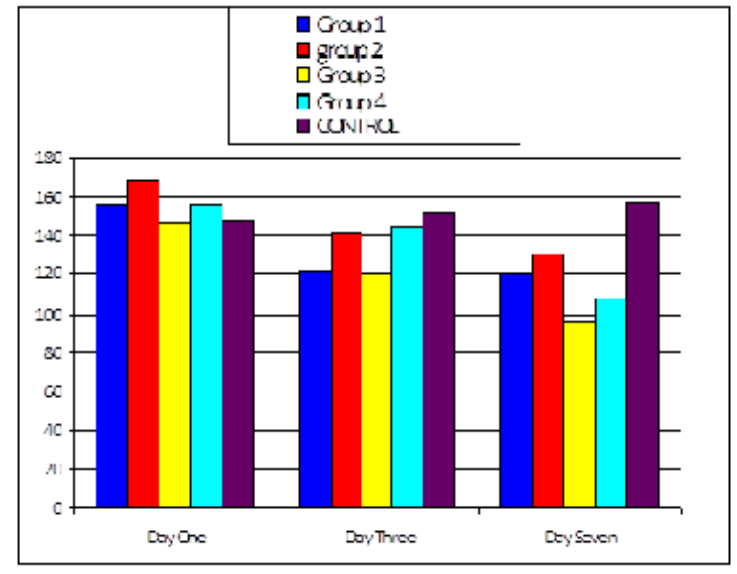

Figure4.1. Change in mean weight $(g)$ in groups $1-4$ after alloxan induction.

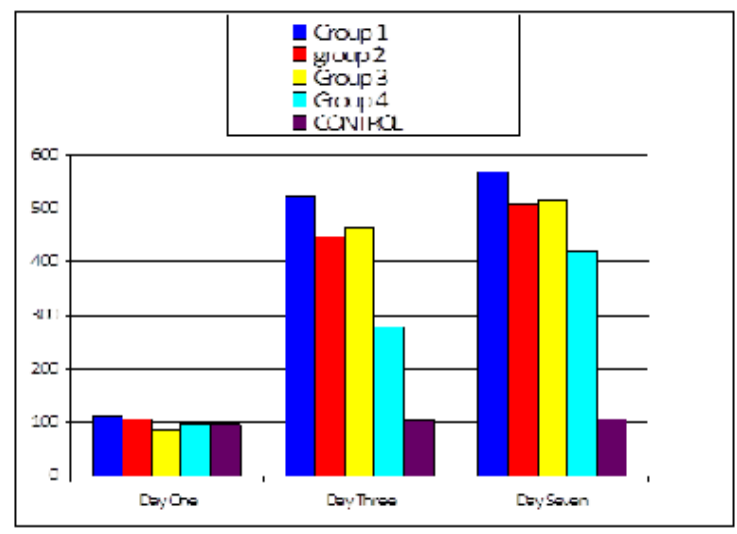

Figure4.2. Change in mean for Glucose level $(\mathrm{mg} / \mathrm{dl})$ in groups 1-4 after alloxan induction.

From figure 4.1 to figure 4.6 we observed consistent rise in the glucose concentration from day 3 and day 7 and decrease in body weight of animals.

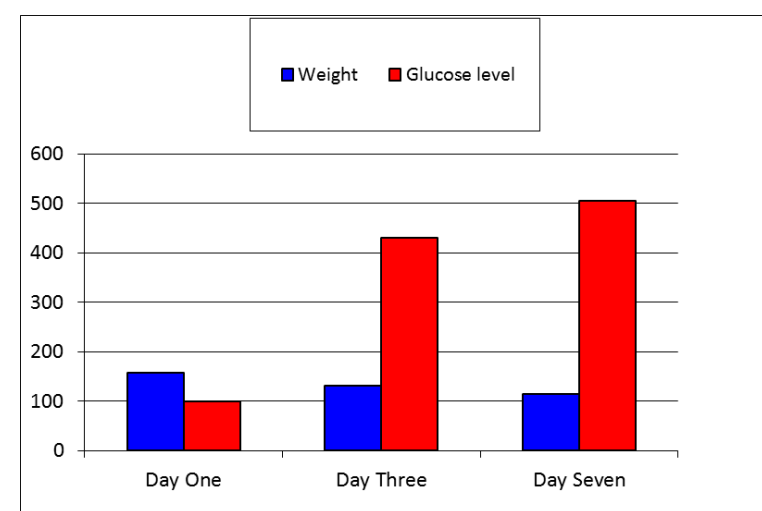

Figure4.3. Change in overall mean weight $(g)$ and Glucose level ( $\mathrm{mg} / \mathrm{dl})$ in groups 1-4.

Here we observes progressive decrease in weight and increase in glucose level.

The overall comparison with the three groups showed no significant difference in glucose level because the p-value is $0.127 \quad(\mathrm{P}>0.05)$ while the weight showed high significant difference for $(\mathrm{P}<0.01)$ when compared with control group.
Table4.2. Test of Significant Difference across the Groups.

\begin{tabular}{|c|c|c|c|c|c|}
\hline & \begin{tabular}{|l|} 
Tryptop \\
han\&Da \\
onil \\
X \pm SE \\
(Min \\
Max) \\
\end{tabular} & \begin{tabular}{|l|} 
Tryptop \\
han \\
Only \\
X \pm SE \\
$($ Min \\
Max $)$ \\
\end{tabular} & \begin{tabular}{|l} 
Daonil \\
Only \\
$(\mathrm{X} \pm \mathrm{SE})$ \\
$(\mathrm{Min}$ \\
$\mathrm{Max})$
\end{tabular} & \begin{tabular}{|l|} 
Control \\
$\mathrm{X} \pm$ SE \\
$(\mathbf{M i n}$ \\
Max $)$
\end{tabular} & $\begin{array}{l}\text { P- } \\
\text { valu }\end{array}$ \\
\hline $\mathrm{se}$ & \begin{tabular}{|l|}
$2.250 \pm 1$ \\
1.6931 \\
$35.0-$ \\
$20.0)$
\end{tabular} & \begin{tabular}{|l} 
\\
$29.500 \pm$ \\
23.2146 \\
$(-81.0-$ \\
$23.0)$
\end{tabular} & $\begin{array}{l} \\
35.500 \pm 7 \\
8022 \\
(-50.0- \\
17.5)\end{array}$ & \begin{tabular}{|l}
$-1.167 \pm$ \\
1.7159 \\
$(-5.0-$ \\
$5.5)$
\end{tabular} & ( \\
\hline it & \begin{tabular}{|l}
$5.500 \pm 3$. \\
$9264 \mathrm{a}$ \\
$(-5.0-$ \\
$14.0)$
\end{tabular} & $\begin{array}{l}.500 \pm 2.1 \\
794 \mathrm{a} \\
(-7.0- \\
2.0)\end{array}$ & $\begin{array}{l}10.500 \pm 3 . \\
1754 b \\
(-19.0- \\
4 .)\end{array}$ & $\begin{array}{l}1.667 \pm \\
2108 \mathrm{a} \\
(-2.0- \\
1.0)\end{array}$ & $\overline{O C}$ \\
\hline
\end{tabular}

NOTE: $\mathrm{P}>0.05=$ no significant difference, $\mathrm{P}<0.01$ $=$ high significant difference. Similar alphabets indicate means with no significant difference

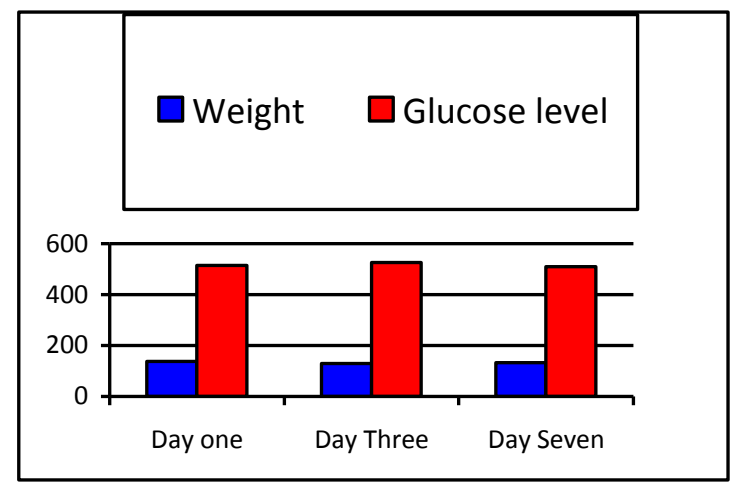

Figure4.4. Change in mean value for weight $(g)$ and glucose level $(\mathrm{mg} / \mathrm{dl})$ in treatment with tryptophan and daonil only.

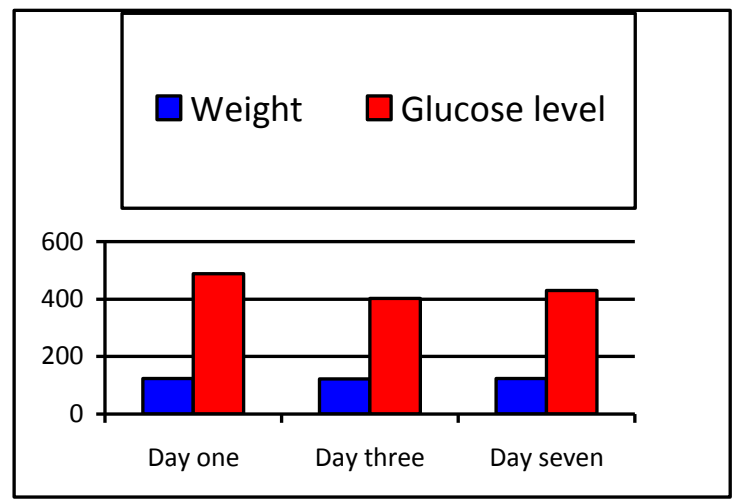

Figure4.5. Change in mean value for weight $(g)$ and glucose levels $(\mathrm{mg} / \mathrm{dl})$ in treatment with tryptophan only

The chart shows no change in weight throughout the days of treatment but there was minimal change in glucose level especially on the third day. 


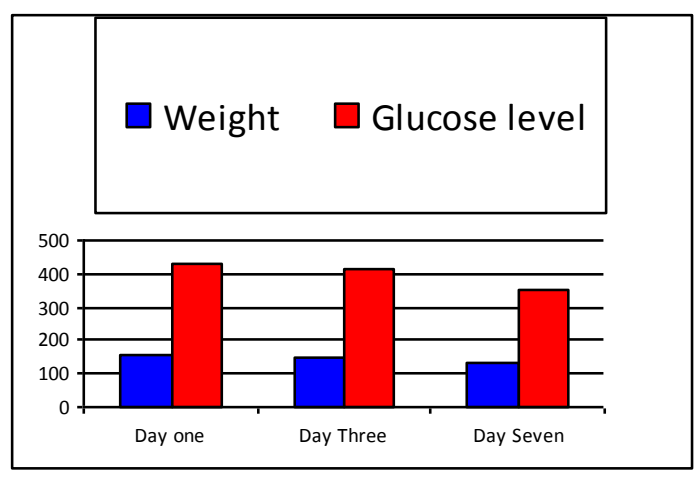

Figure4.6. Change in mean value for weight and Glucose level in treatment with daonil only.

This chart shows progressive decrease in glucose level especially the seventh day but, there was little or no change in weight.

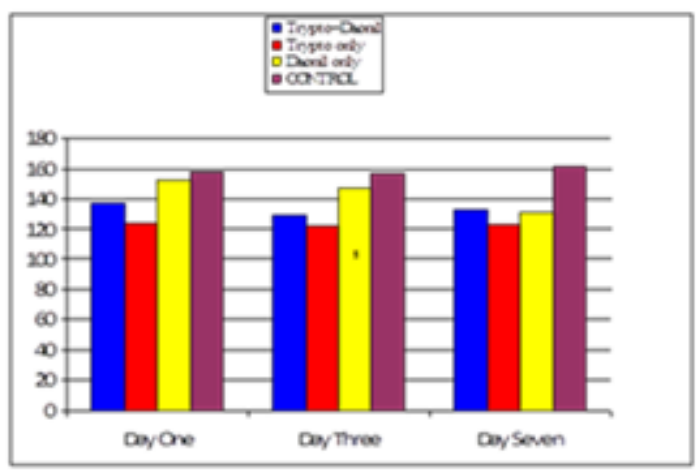

Figure4.7. Change in mean weight $(g)$ in the three treatment groups.

In this chart we observed minimal weight lost with the three groups and this is more noticeable on the seventh day, but when compared with the control group there was weight gain.

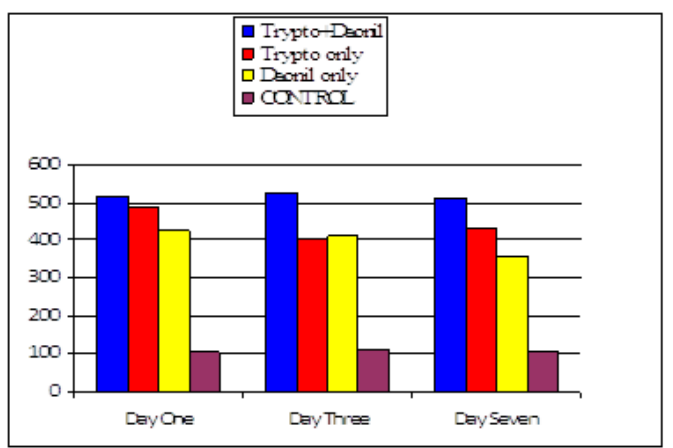

Figure4.8. Change in mean Glucose level $(\mathrm{mg} / \mathrm{dl})$ in the three treatment groups.

Kidney x 100

Control



Tryptophan \& Daonil Tryptophan only

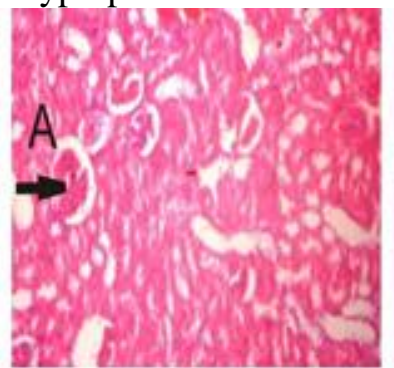

Fig 4.8 shows mean difference in glucose level for the different treatment group. Here we observed there was no significant decrease in the glucose level in both tryptophan and daonil group and tryptophan only group but there was significant decrease in the daonil only, while in the control group no such difference was observed. One thing of note is that the three treatments showed observable change on the third day when compared to the seventh day.

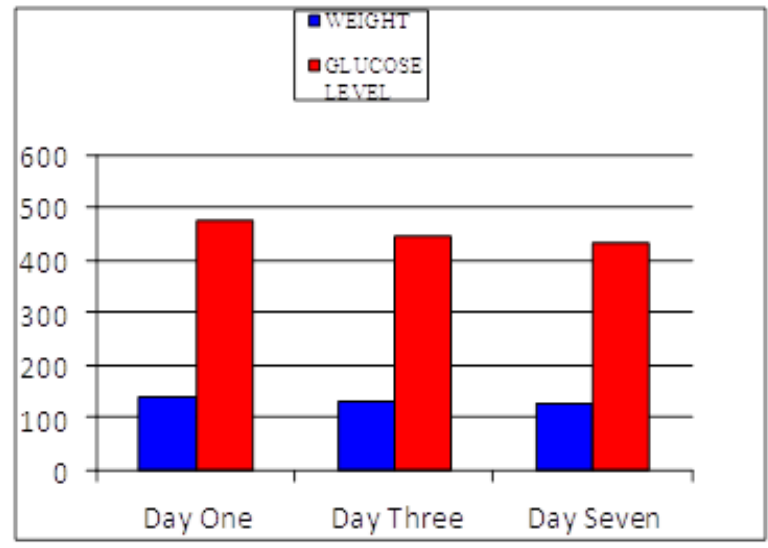

Figure4.9. Change in overall mean in Glucose level $(\mathrm{mg} / \mathrm{dl})$ and weight $(\mathrm{g})$ in the three treatment groups.

Here there is no change in the overall mean weight in the three treatment group but there was an observable decrease in the overall change in the glucose level.

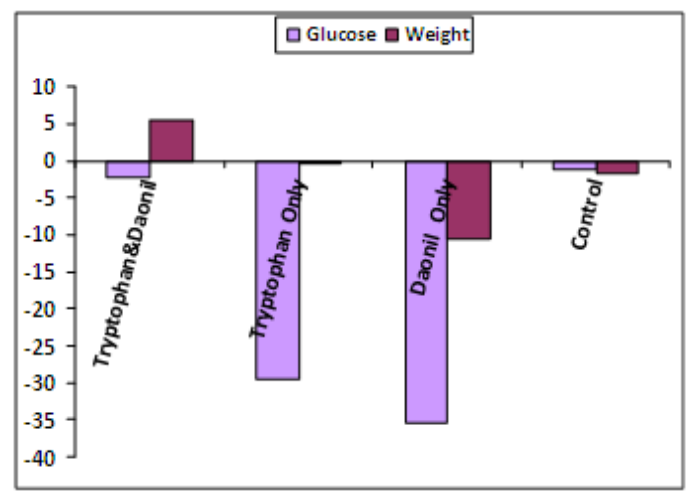

Figure4.10. Chart showing mean weight and glucose level of the three treatment groups.

Here we observed a negative correlation in the three groups expect in the weight in the tryptophan and daonil group

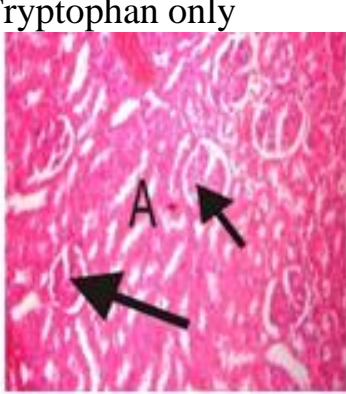

Daonil only

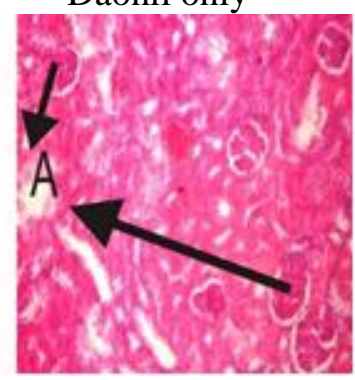




\subsection{Kidney (Control)}

Kidney section show normal histological features. The section indicated a detailed cortical parenchyma (A) and the renal corpuscles appeared as dense rounded structures (B)

\subsection{Kidney (Tryptophan and Daonil)}

Kidney section show histological features. The section indicated a detailed cortical parenchyma (A) and the renal corpuscles appeared as atrophied dense rounded structures (B)

Liver $\mathrm{x} 100$

Control

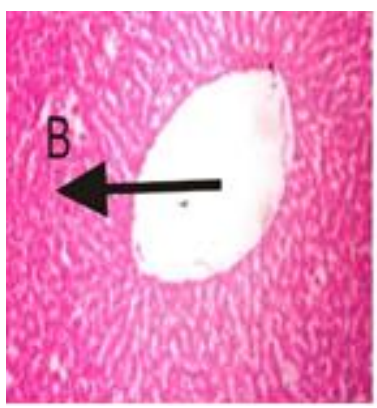

\subsection{Liver (Control)}

Prominent histology feature showing portal vein (B) well fenestrated sinusoids and hepatocytes with distinct nucleus (A)

\subsection{Liver (Tryptophan and Daonil)}

Prominent histology feature showing portal vein (A) appearing slightly congested with some inflammatory cells (B)

sPancreas $\mathrm{x} 100$
Control

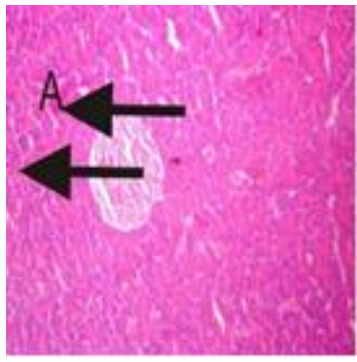

Tryptophan \& Daonil



\subsection{Pancreas (Control)}

Pancreas reveal acinar pattern structure, (A) pyknotic nuclei of some acinar cells appear normal with some islet-cells showing pyknotic nuclei. The acinar cells which stained strongly are arranged in lobules with prominent nuclei. The islet cells are seen embedded within the acinar cells and surrounded by a fine capsule (B).

\subsection{Kidney (Tryptophan Only)}

Kidney section show normal histological features. The section indicated a detailed cortical parenchyma (A) and the renal corpuscles appeared as dense rounded structures (B).

\subsection{Kidney (Daonil Only)}

Kidney section show histological features. The section indicated a detailed cortical parenchyma (A) and the renal corpuscles appeared as dense rounded structures bounded by inflammatory infiltrates(B).

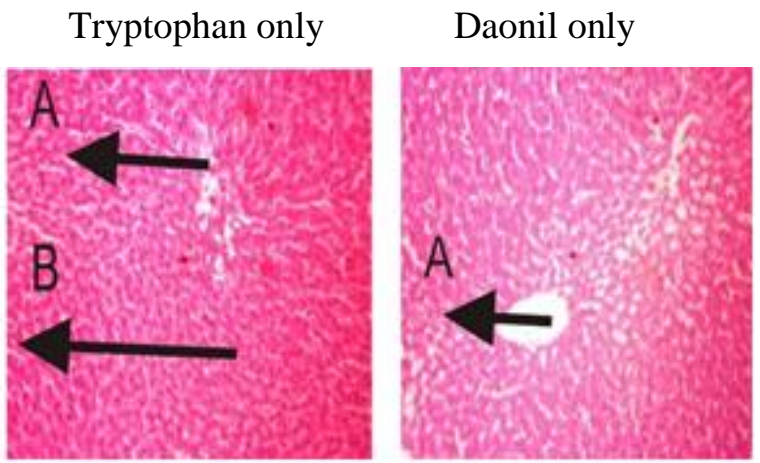

\subsection{Liver (Tryptophan Only)}

Prominent histology feature showing distorted portal vein (A) appearing slightly congested with visible inflammatory cells (B).

\subsection{LIVER (Daonil)}

Prominent histology feature showing thickened portal vein (A) appearing clear with visible fatty hydropic changes (B).
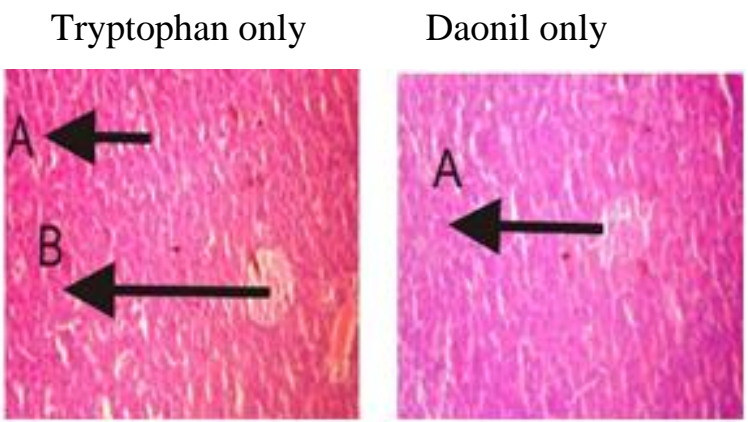

\subsection{Pancreas (Tryptophan and Daonil)}

Pancreas reveal acinar pattern structure, (A) pyknotic nuclei of some acinar cells appear normal with some islet-cells showing congested pyknotic nuclei. (B)

\subsection{Pancreas (Tryptophan only)}

Pancreas reveals some normal islet cells present with Lymphocytes. 


\subsection{Pancreas (Daonil Only)}

Pancreas reveal acinar pattern structure, (A)

Kidney (X400)

Control

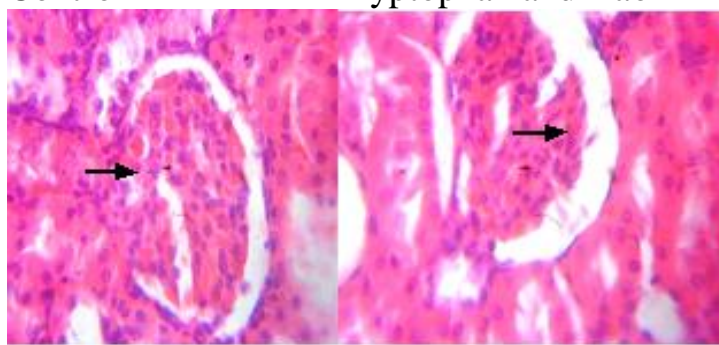

Control Kidney section shows normal histological features with detailed cortical parenchyma and the renal corpuscles appeared as dense rounded structures (arrow). Tryptophan and Daonil Kidney section indicated a detailed cortical parenchyma and the renal corpuscles appeared as atrophied dense rounded

Liver (X400)

Control Tryptophan and Daonil

Some normal islet cells are also present with Lymphocyte(B).

Tryptophan Only

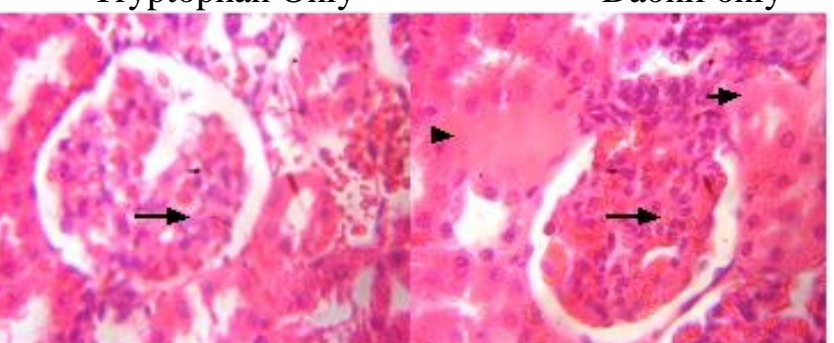

structures (arrow). Tryptophan section show histological features same as the control but with few inflammatory cells. Daonil Kidney section show histological features with a detailed cortical parenchyma (arrow) and the renal corpuscles appeared as dense rounded structures bounded by prominent inflammatory infiltrates (arrow head).

Tryptophan Only

Daonil Only

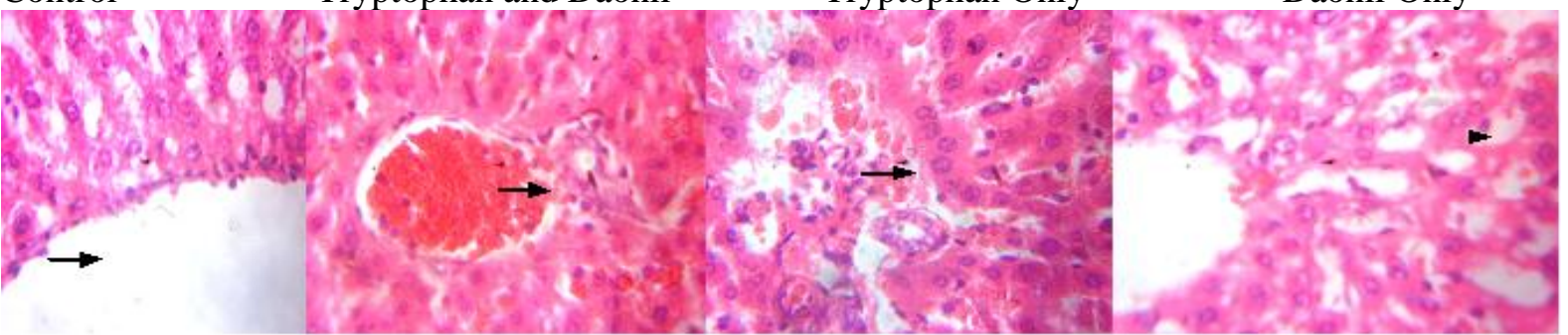

Control section shows prominent histology feature showing portal vein (arrow) well fenestrated sinusoids and hepatocytes with distinct nucleus. Tryptophan and Daonil sections shows prominent histology feature showing portal vein (arrow) appearing slightly congested with scanty inflammatory cells Pancreas(X400) magnification surrounding it. Tryptophan section showing distorted portal vein (arrow) appearing slightly congested with visible inflammatory cells. Daonil feature showing thickened portal vein (arrow) appearing clear with visible fatty hydropic changes (arrow head).

Tryptophan and Daonil control

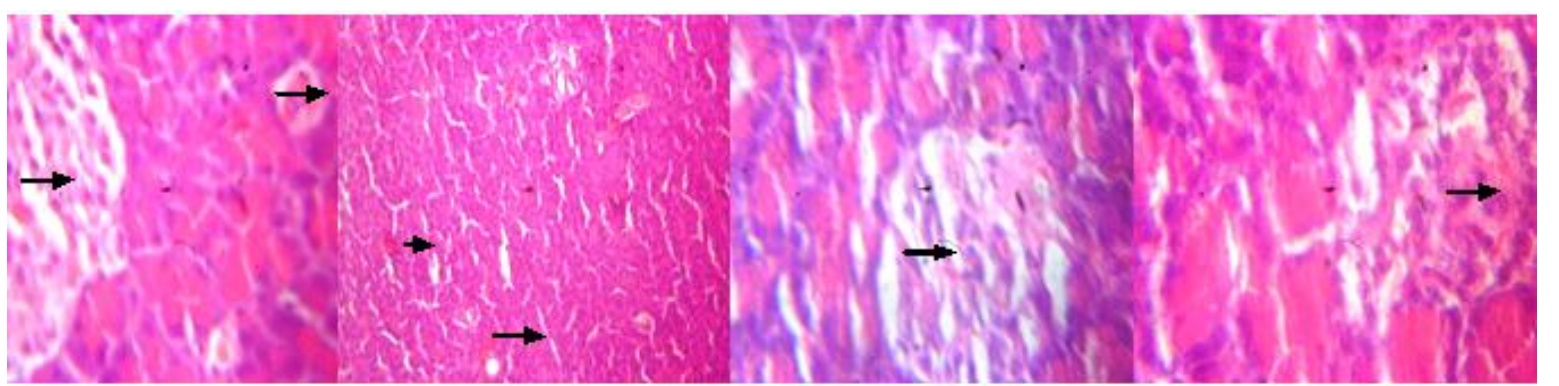

Control pancreas reveals acinar pattern structure with pyknotic nuclei of some acinar cells appearing. The acinar cells which stained strongly are arranged in lobules with prominent nuclei. The islet cells are seen embedded within the acinar cells and surrounded by a fine capsule (arrow). Tryptophan and Daonil features show some acinar cells appearing normal with some islet-cells showing congested pyknotic nuclei.
Tryptophan only reveals some normal islet cells and also present with Lymphocytes (arrow). Daonil only reveals some normal islet cells with visible Lymphocytic infiltrates.

\section{CONCLUSiON}

The findings in this study indicate that diabetes had deleterious effect on the kidney, liver and pancreas due to drug administration. Tryptophan and daonil combination have no good effect on 
alloxan induced diabetic animals and therefore cannot be a good alternative in diabetes management. Daonil was found to lower blood glucose level in alloxan induced diabetic animal model even within few days of treatment.

\section{RECOMMENDATION}

From this study alloxan administration to experimental animals caused pancreatic lesion, which was proportional to the dose of the drug administered, and the lesion size correlates with the pancreatic insulin content. For this reason $150 \mathrm{mg} / \mathrm{kg}$ of alloxan was used for this study, because at a low or medium dose the drug produces insufficient insulin deficiency rather than absolute deficiency in experimental animals. However in order to avoid excessive pancreatic tissue damage the experimental dose of the drug was carefully selected [27].The animals were put to use within seven days after induction of diabetes mellitus because this was advisable. For the establishment of diabetes mellitus with alloxan, there was progressive rise in glucose concentration from the $3^{\text {rd }}$ to the $7^{\text {th }}$ day and reduction in weight before the commencement of treatment. However it was observed that two out of twenty five rats induced with alloxan were not diabetic. This probably could be due to the fact that for alloxan to cause injury to beta cells, there must be genetic susceptibility. These susceptibility to alloxan diabetogenic and toxic effects differs among animals of the same species. Such unpredictable responses with alloxan have also been reported by authors in the past [28].The resistance of some rats to alloxan suggests genetic differences in the constitutive ability to dissipate reactive oxygen species responsible for diabetogenic effect of alloxan [29].This effect of alloxan however, remains contradictory to other studies where alloxan has been successfully used for the same. Mortality was observed in our study with alloxan, which was also reported in previous studies this was either due to initial hypoglycaemic shock, direct toxicity of kidney tubular cell or emergence of diabetic complications [30]. It was observed from this study that the daonil supplemented tryptophan resulted in minimal change in both the weight and glucose concentration, but daonil only had significant reduction on the weight and glucose concentration, this was more noticeable on the $7^{\text {th }}$ day. The oral administration of tryptophan did not change the glycaemia level this was also observed in the course of this study [31]. The results obtained from other investigation suggested that tryptophan suppresses the elevation of blood glucose and lessens the burden associated with insulin secretion from $\beta$ cells, this agrees with our findings in which there was a decrease in glucose level on day $7^{\text {th }}$ in the group treated with tryptophan only. We also observed no significant increase in glucose level with $400 \mathrm{mg} / \mathrm{kg}$ tryptophan treatment though previous work observed that oral administration of $400 \mathrm{mg}$ of tryptophan resulted in marked increases in blood glucose in diabetic rats, that tryptophan appeared to be about onefourth as active as glucose in elevating the blood glucose in diabetic rats. The increase in blood glucose levels resulting from administration of tryptophan to diabetic rats suggests that these rats may convert tryptophan to glucose in an attempt to supply energy rather than converting it to niacin. However tryptophan was probably not converted to glucose, but promoted the formation of glucose in some indirect manner [15]. Tryptophan and daonil treatment showed no remarkable change in glucose level, which could be due to interactions. However, in clinical setting tryptophan has not been thoroughly studied, therefore its possible side effects and interactions with other drugs are not well known [32]. The transport system which brings tryptophan across the blood-brain barrier is selective compared to other amino acids which are contained in protein food sources thus consumption of dietary tryptophan supplement could increase brain serotonin thereby causing serotonin syndrome whereas eating foods containing tryptophan may not [33]. Hence using tryptophan supplement in diabetes may worsen the condition therefore should not be encouraged, as found in this study. Besides the possible relationships between tryptophan with diseases and metabolic disorders like diabetes are linked to its important role in physiological (nerve transmission, immune response) and pathological processes (stress, depression, sleep and appetite disorders) which leads to changes in mood, behaviour, anxiety, sleep, fatigue and appetite suppression were also observed in this study. This findings agrees with the earlier works done by [12]. Histological analysis of the kidney showed that the renal corpuscles appeared as atrophied dense rounded structures bounded by inflammatory infiltrates. The liver showed distorted portal vein slightly congested with some inflammatory cells with visible fatty hydropic changes. Pancreatic islet-cells shows congested pyknotic nuclei present with lymphocyte. This findings also agrees with [34] who reported deficient islets cells. 


\section{REFERENCES}

[1] World Health Organisation (2013) Diabetes Fact sheet N³12". Retrieved 25 March 2014.

[2] Kengne, A.P., Amoah, A.G., and Mbanya, J.C. (2005) Cardiovascular complications of diabetes mellitus in sub-Saharan Africa. Circulation. 112: 3592-3601.

[3] World Health Organisation Diabetes Fact sheet N³12". WHO. October 2013. Archived from the original on 26 Aug 2013. 25

[4] Famuyiwa OO., Nwabuebo, I.E., and Abioye, A.A. (1982) Pattern of histocompatibility (HLA) antigen distribution among Nigerian (West African black) diabetics. Diabetes. 31:1119-1122.

[5] De la Monte, S.M. (2014). "Type 3 diabetes is sporadic Alzheimer's disease: mini-review." European neuro-psycho pharmacology: Journal of European College of Neuro-psycho pharmacology 24 (12): 1954-1960.

[6] Malik V.S., Popkin B.M., Bray G.A., Després J.P., and Hu F.B. (2010). "Sugar Sweetened Beverages, Obesity, Type 2 Diabetes and Cardiovascular Disease risk". Circulation 121 (11): 1356-1364.

[7] Osuntokun B.O., Akinkugbe F.M., Francis T.I., Reddy S., Osuntokun O., and Taylor G.O.,(1971) Diabetes mellitus in Nigerians: a study of 832 patients. West African Medical Journal in Nigeria Practice. 20:295-312.

[8] Olatunbosun S.T, Ojo P.O, Fineberg N.S, and Bella A.F. (1998) Prevalence of diabetes mellitus and impaired glucose tolerance in a group of urban adults in Nigeria. Journal of National Medicine Association. 90:293-301.

[9] Hopkins, F.G., and Cole S.W. (1901). "A contribution to the chemistry of proteids: Part I. A preliminary study of a hitherto undescribed product of tryptic digestion". The Journal of Physiology 27 (4-5): 418-428.

[10] Zhang L.S., Davies S.S (2016). "Microbial metabolism of dietary components to bioactive metabolites: opportunities for new therapeutic interventions". Genome Medicine 8 (1): 46.

[11] Molnár-perl, I.; (2007) Advancements in the rapid and sensitive analysis of tryptophan and its metabolites, by chromatography. International Congress Series Journal. 1304, 389-403.

[12] Del bem, C. M.; (2005) Quantification of tryptophan in plasma by high performance liquid. Revista Brasileira de Psiquiatria Clinicalia. 32, 27.

[13] Afaghi, A., O'Connor, H., and Chow, C.M. (2007). "High-glycemic-index carbohydrate meals shorten sleep onset". The American Journal of Clinical Nutrition 85 (2): 426-430.
[14] Maher, T.J., Glaeser, B.S., and Wurtman, R.J (1984). "Diurnal variations in plasma concentrations of basic and neutral amino acids and in red cell concentrations of aspartate and glutamate: effects of dietary protein intake". The American Journal of Clinical Nutrition 39 (5): 722-729.

[15] Inubushi, T, Kamemura, N, Oda, M, Sakurai, J, Nakaya Y, Harada, N, Suenaga, M, Matsunaga, Y, Ishidoh, $\mathrm{K}_{.}$, and Katunuma, N. (2012) L-tryptophan suppresses rise in blood glucose and preserves insulin secretion in type2 diabetes mellitus rats. Journal of Nutritional Science Vitaminology (Tokyo). 58(6):415-422.

[16] Radwanski E.R., and Last R.L. (1995). "Tryptophan biosynthesis and metabolism: biochemical and molecular genetics". The Plant Cell 7 (7): 921-934.

[17] Federiuk, I.F., Casey, H.M., Quinn, M.J., Wood, M.D., and Ward, W.K. (2004). Induction of type 1 diabetes mellitus in laboratory rats by use of alloxan; route of administration, pitfalls, and insulin treatment. Comprehensive Medicine 54: 252-257.

[18] Tydberg B, Andersson A, Borg L. (2001) Species differences in susceptibility oftransplanted and cultured pancreatic islets to the beta-cell toxin alloxan. General and Comparative Endocrinology 122: 238-251.

[19] Viana G.S, Medeiros A.C, Lacerda A.M, Leal L.K, Vale sT.G, Matos F.J. (2004). Hypoglycemic and anti-lipemic effects of the aqueous extract from Cissus sicyoides.BMC Pharmacol, 8: 4-9.

[20] Marble A (1971). "Glibenclamide, a new sulphonylurea: whither oral hypoglycaemic agents? Drugs. 1 (2): 109-115.

[21] Serrano-Martín X, Payares G, and MendozaLeón A (2006). "Glibenclamide, a blocker of $\mathrm{K}+$ (ATP) channels, shows anti leishmanial activity in experimental murine cutaneous leishmaniasis". Antimicrobial. Agents Chemo therapy. 50 (12): 4214-4216.

[22] Meloni G, Meloni T (1996). "Glyburideinduced acute haemolysis in a G6PD-deficient patient with NIDDM". British Journal of Haematology 92 (1): 159-160.

[23] Monami M, Luzzi C, Lamanna C, Chiasserini V,Marchionni N, and Mannucci E (2006). "Three-year mortality in diabetic patients treated with different combinations of insulin secretagogues and metformin". Diabetes Metabolism Research Review. 22 (6): 477482.

[24] Yanarday R., Colac H. (1998). Effect chard (Beta vulgaris L. varcicla) on blood glucose level in normal and alloxan induced diabetic rabbit. Journal of Ethnophamarcy. 4:309-311. 
[25] Lipkowski, J., Kolb, D. M., and Alkire, R. C. (2011). Bioelectrochemistry: Fundamentals, Applications and Recent Developments. Weinheim: Wiley-VCH.

[26] Avwioro,G. (2011) Histochemical Uses of Haematoxylin - A Review. Journal of Pharmacy and Clinical Sciences 1; 24-34

[27] McNeill J.H. (1990). Experimental models of diabetes. Information health care. pp 8.

[28] Zhao Z.H., Watschinger B., Brown C.D., Beyer M.M., Friedman E.A. (1987) Variations of susceptibility to alloxan induced diabetes in the rabbit. Horm Metabolic Research. 19:534-537.

[29] Mathews C.E, and Leiter E.H. (1999) Constitutive differences in antioxidant defense status distinguish alloxan-resistant and alloxansusceptible mice. Free Radical Biological Medicine. 27: 449-455.

[30] Szkudelski T. (2001) The mechanism of alloxan and streptozotocin action in B cells of the rat pancreas. Physiological Research .50:537-546.
[31] Tormo, M. A., Romerode de Tejada A., Morales, I., Paredes, S., Sanchez, S., Barrga, C., Hernandez, R. (2004) Orally administered tryptophan and experimental Type 2 Diabetes 262 (1-2); 57-61.

[32] Shaw K., Turner J., Del Mar C., and Shaw K.A. (2002) "Tryptophan and 5-hydroxytryptophan for depression". The Cochrane Database of Systematic Reviews (1): 6 124-146.

[33] Howland, R.H. (2012). "Dietary supplement drug therapies for depression". Journal of Psychosocial Nursing and Mental Health Services 50 (6): 13-16

[34] Dobrovolsky, V. N., Bucci, T., Heflich, R. H., Desjardins, J., and Richardson, F.C. (2003). Mice deficient for cytosolic thymidine kinase gene develop fatal kidney disease. Molecular Genetics and Metabolism.78, 1-10.

Citation: Emili Augustina Mmaduaburochukwu, Osadolor H.B, Omorodion Nosa Terry, Ibeh N.I. Palliative Effects of Daonil Supplemented with Tryptophan on Alloxan Induced Diabetic Rats. ARC Journal of Anesthesiology. 2017;2(1):12-23. doi: dx.doi.org/10.20431/2455-9792.0201004.

Copyright: (C) 2017 Authors. This is an open-access article distributed under the terms of the Creative Commons Attribution License, which permits unrestricted use, distribution, and reproduction in any medium, provided the original author and source are credited. 